\title{
V-Shaped SmC* switching FLC compounds
}

\author{
V. Bezborodov, V. Lapanik, G. Sasnouski \\ Institute of Applied Physics Problems, Minsk 220064, Belarus'
}

\begin{abstract}
Chiral aryl esters of 4-alkyl-3-chlorobiphenyl-4'-carboxylic and 4-(6-alkylcyclohex-2-enonoyl-3)benzoic acids have been synthesized. The phase transition temperatures and $\mathrm{V}$-shaped $\mathrm{SmC}^{*}$ switching of the prepared compounds are discussed.
\end{abstract}

Keywords: liquid crystals, synthesis, biphenyls, phenylcyclohex-2-enones

\section{INTRODUCTION}

In the previous publication ${ }^{1}$ we have shown that chiral aryl esters of 4-alkyl-3-chlorobiphenyl-4-carboxylic acids form smectic $\mathrm{C}$ phase at low temperature and in a wide temperature range. In continuation of these investigations and in an attempt to obtain new promising components of the ferroelectric liquid crystalline materials for display applications we have synthesized the new chiral aryl esters of 4-alkyl-3-chlorobiphenyl-4'-carboxylic and 4-(6-alkylcyclohex-2-enonoyl3)benzoic acids and investigated the mesomorphic, physical and electrooptical properties of the FLC compositions on their base

\section{RESULTS AND DISCUSSION}

4-Alkyl-3-chlorobiphenyl-4'-carboxylic and 4-(6-alkylcyclohex-2-enonoyl-3)benzoic acids $(2,4)$ were prepared by the hydrolysis of 4-(6-alkylcyclohex-2-enonoyl-3)benzonytriles (1) and 4-alkyl-3-chloro-4'-cyanobiphenyls (3) in boiling ethylene glycol in the presence of potassium hydroxide. 4-(6-Alkylcyclohex-2-enonoyl-3)benzonytriles (1) we synthesized with a yield 50-70\% by Michael condensation of hydrochloride of 4-(2-dimethylaminopropionyl)-benzonitryle with 2alkylacetoacetic esters accordingly to our published method ${ }^{2,3}$. The esters $(5$ a-d) and $(6 \mathrm{a}, \mathrm{b})$ (tables 1 and 2$)$ were synthesized by the interaction of the acids (2) or (4) with chiral 4-substituted phenols in the presence of dicyclohexylcarbodiimide (DCC) and 4-dimethylaminopyridine as catalyst.

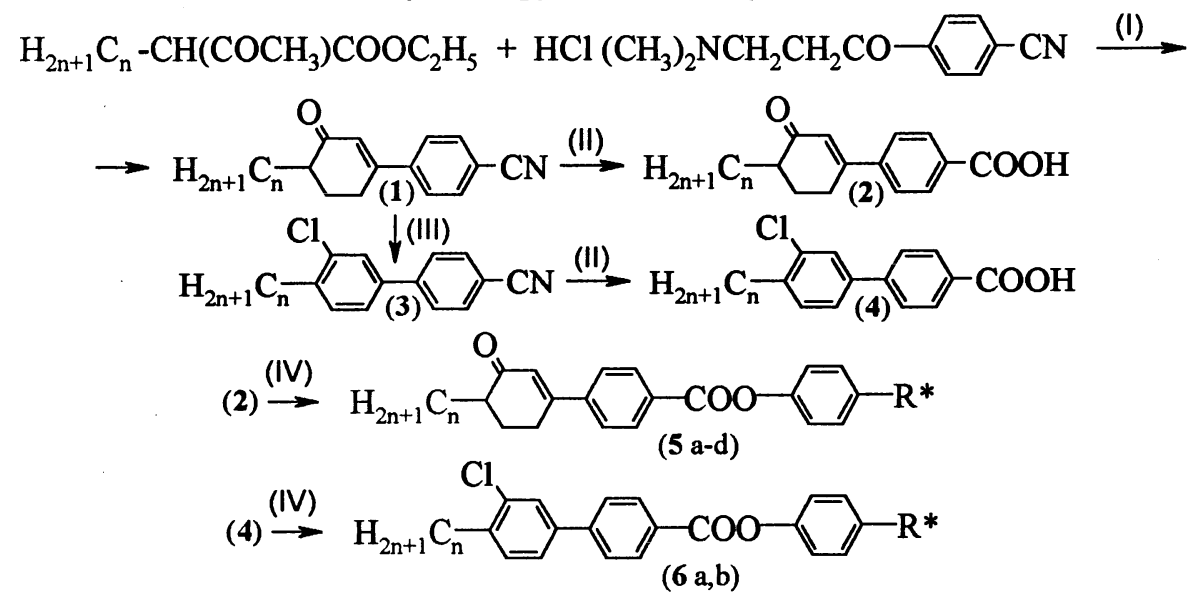

$\mathrm{n}=8,10 ; \mathrm{R}^{*}=\mathrm{OCH}_{2} \mathrm{CH}\left(\mathrm{CH}_{3}\right) \mathrm{OC}_{2} \mathrm{H}_{5}, \mathrm{O}\left(\mathrm{CH}_{2}\right)_{3} \mathrm{CH}\left(\mathrm{CH}_{3}\right) \mathrm{C}_{2} \mathrm{H}_{5}, \mathrm{COOCH}\left(\mathrm{CH}_{3}\right) \mathrm{C}_{6} \mathrm{H}_{13}$, $\mathrm{OCH}\left(\mathrm{CH}_{3}\right) \mathrm{COOCH}_{3}, \mathrm{C}_{6} \mathrm{H}_{4} \mathrm{COOCH}\left(\mathrm{CH}_{3}\right) \mathrm{C}_{6} \mathrm{H}_{13}$.

I. KOH, dioxan; II. KOH, ethylene glykol; III. PCl, IV HOPhR*, DCC, DMAP. 
Table 1. Transition temperatures of the esters $(5 \mathrm{a}-\mathrm{d})$

\begin{tabular}{|c|c|c|c|c|c|c|c|c|}
\hline \multirow[t]{2}{*}{$\mathrm{N}$} & \multirow[t]{2}{*}{$\mathrm{R}^{*}$} & \multicolumn{4}{|c|}{ Transition } & \multicolumn{2}{|c|}{ temperatures $/{ }^{\circ} \mathrm{C}$} & \multirow[b]{2}{*}{$\mathrm{I}$} \\
\hline & & $\mathrm{Cr}$ & & $\mathrm{Sm} \mathrm{C}$ & & $\mathrm{Sm} \mathrm{A}$ & & \\
\hline $\mathbf{a}$ & $\mathrm{OCH}_{2} \mathrm{CH}\left(\mathrm{CH}_{3}\right) \mathrm{OC}_{2} \mathrm{H}_{5}$ & $\bullet$ & 52 & $\bullet$ & 98 & $\bullet$ & 165 & $\bullet$ \\
\hline b & $\mathrm{O}\left(\mathrm{CH}_{2}\right)_{3} \mathrm{CH}\left(\mathrm{CH}_{3}\right) \mathrm{C}_{2} \mathrm{H}_{5}$ & $\bullet$ & 62 & $\bullet$ & 138 & $\bullet$ & 190 & $\bullet$ \\
\hline c & $\mathrm{OCH}\left(\mathrm{CH}_{3}\right) \mathrm{COOCH}_{3}$ & $\bullet$ & 44 & $\bullet$ & 69 & $\bullet$ & 120 & $\bullet$ \\
\hline d & $\mathrm{COOCH}\left(\mathrm{CH}_{3}\right) \mathrm{C}_{6} \mathrm{H}_{13}$ & $\bullet$ & 57 & $\bullet$ & 121.5 & $\bullet$ & 122.5 & $\bullet$ \\
\hline
\end{tabular}

Table 2. Transition temperatures of the esters $(6 a, b)$

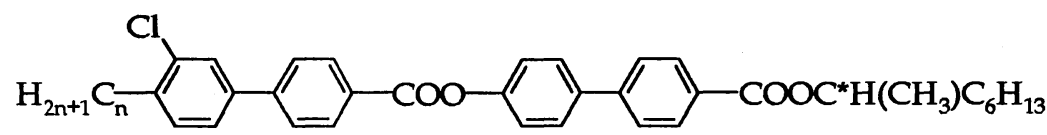

\begin{tabular}{lcccccccc}
\hline n & \multicolumn{7}{c}{ Transition } & \multicolumn{7}{c}{ temperatures $/{ }^{\circ} \mathrm{C}$} \\
\cline { 2 - 9 } & $\mathrm{Cr}$ & $\mathrm{Sm} \mathrm{A}$ & \multicolumn{2}{c}{$\mathrm{Sm} \mathrm{C}$} & & $\mathrm{Sm} \mathrm{A}$ & & $\mathrm{I}$ \\
\hline a 5 & $\bullet(34)$ & $\bullet$ & 98 & $\bullet$ & 117 & $\bullet$ & 184 & $\bullet$ \\
b 10 & $\bullet$ & - & 72 & $\bullet$ & 138 & $\bullet$ & 156 & $\bullet$ \\
\hline
\end{tabular}

A

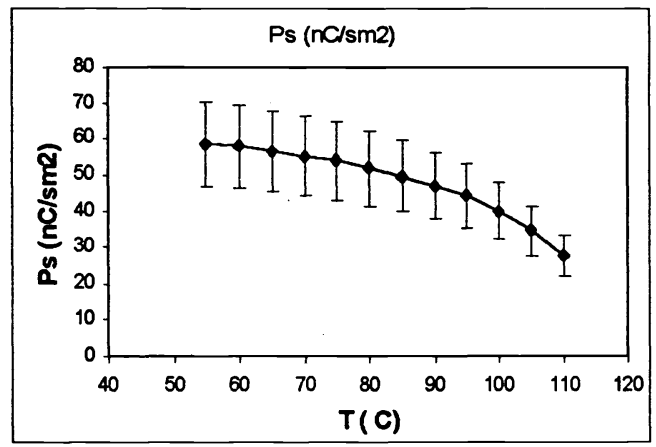

B
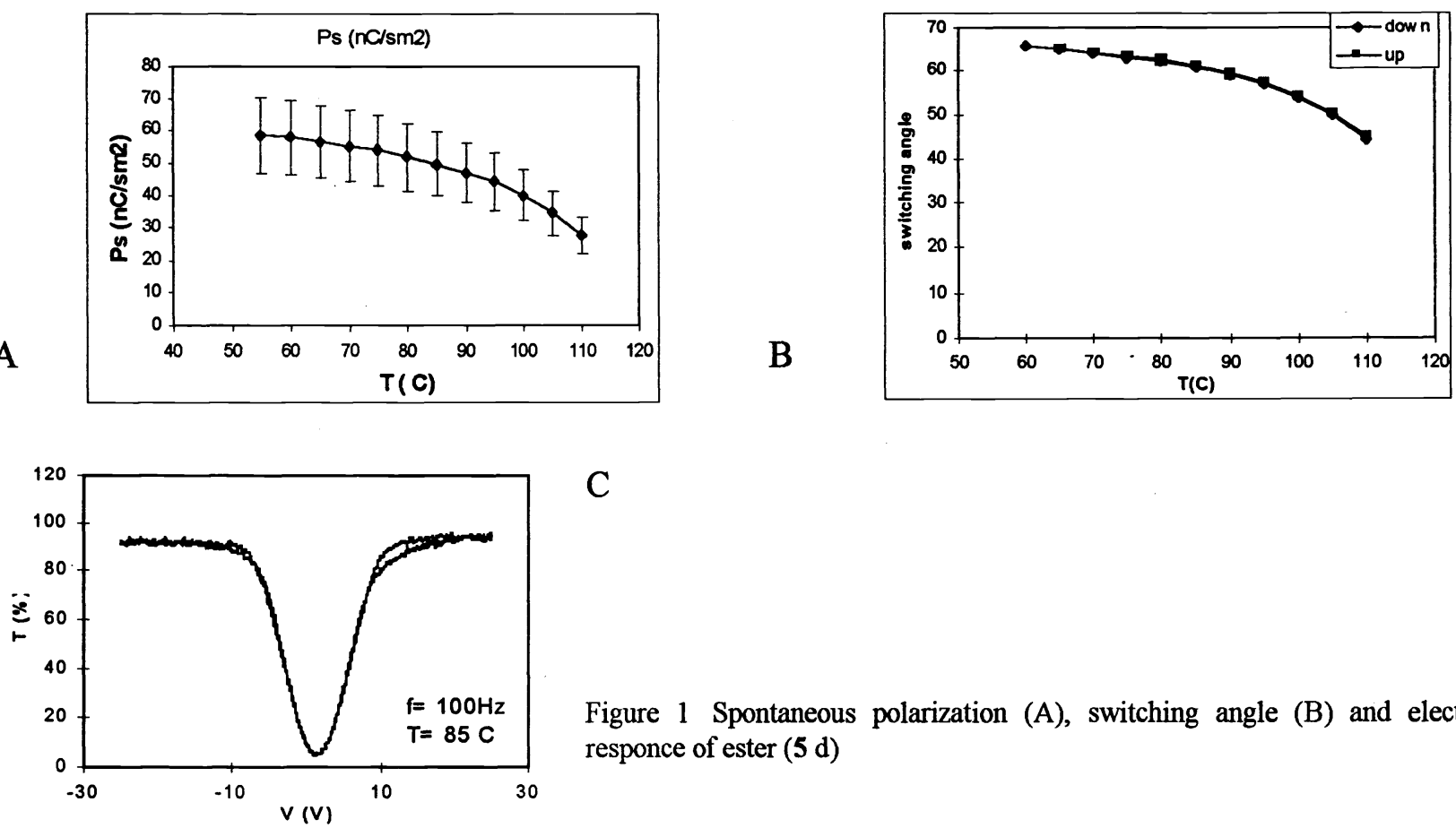

$\mathrm{C}$

Figure 1 Spontaneous polarization (A), switching angle (B) and electro-optic responce of ester $(5 \mathrm{~d})$

As it can be seen from tables 1 and 2 prepared esters $(5 \mathrm{a}-\mathrm{d} ; 6 \mathrm{a}, \mathrm{b})$ are strongly smectogenic compounds forming smectic $\mathrm{A}$ and smectic $C^{*}$ phases at low temperature and in a wide temperature range.

Our investigations have shown that the spontaneous polarization of the esters (5 a-d) is not high and varied from 20 till 80 $\mathrm{nC} / \mathrm{cm}^{2}$ in dependence from the chemical structure of the compounds (figures $1 \mathrm{~A}$ and $1 \mathrm{~B}$ ). Anyway, hysteresis free 
transmission voltage curves, V-shaped or thresholdless switching are observed for them and for FLC mixtures on their base in a wide temperature range and at different frequencies (figures $1 \mathrm{C}$ and 2). Detail investigations have shown that these materials are really ferroelectric and not antiferroelectric and such behaviour can be explained by specific geometry of the molecules of the esters (5 a-d) (fig 3) and strong lateral polar interactions of cyclohex-2-enone fragment with the surface.
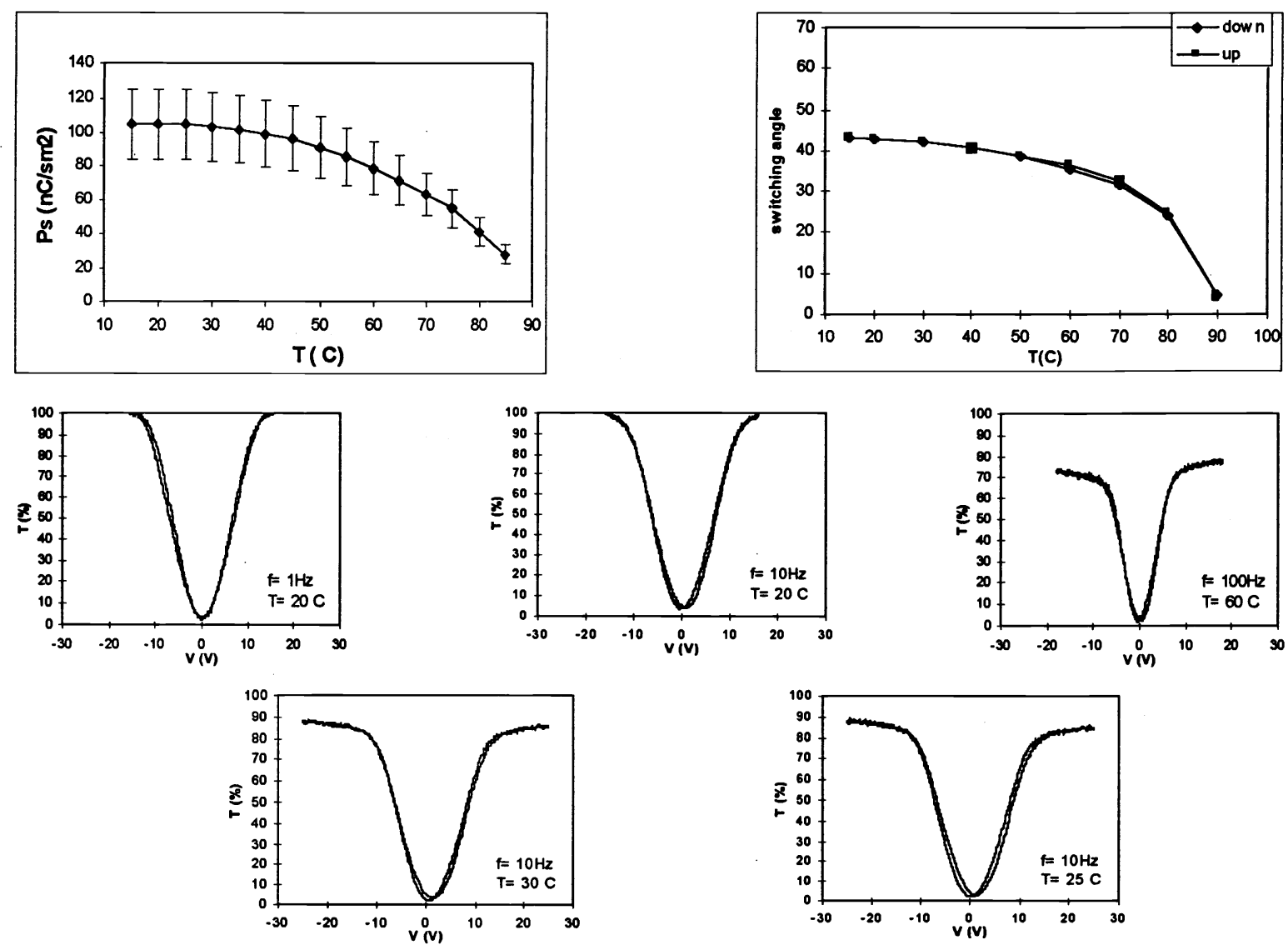

Figure 2 Spontaneous polarization, switching angle and electro-optic responce of FLC mixture of esters (5 a, b and d)
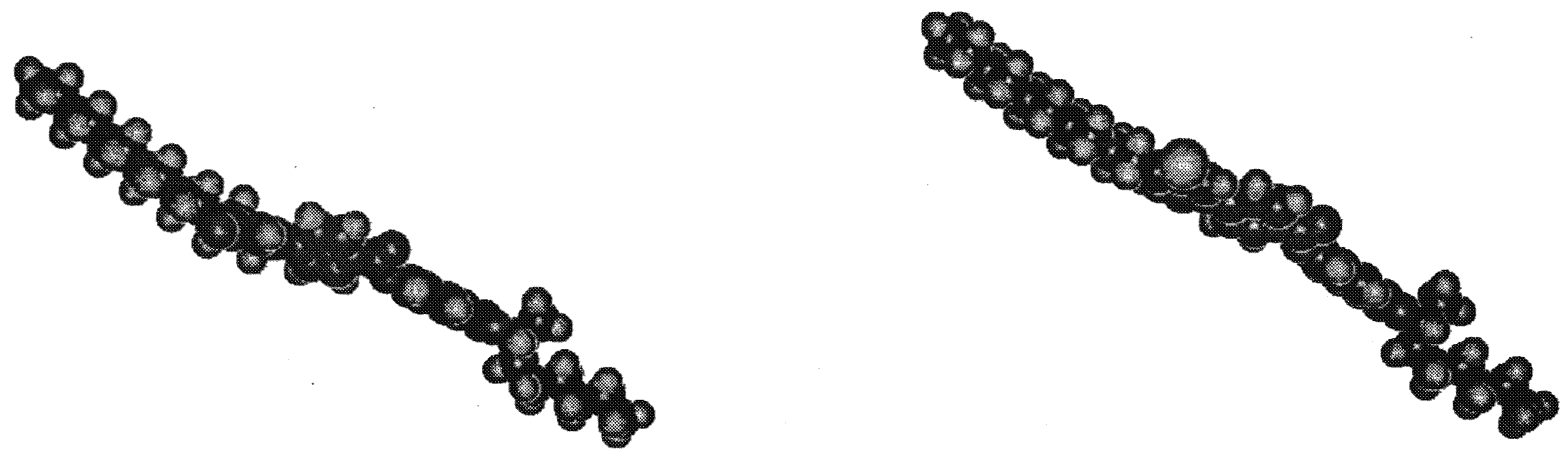

Figure 3 Molecular model of the ester (5d)

Figure 4 Molecular model of the ester (6a) 
Our additional investigations have shown that V-shaped switching is observed for some the chiral aryl esters of of 4alkyl-3-chlorobiphenyl-4-carboxylic acids (6 a,b) (fig 4) ${ }^{1}$. But, unlike the cyclohex-2-enones derivatives (5a-d), these compounds and the FLC compositions on their base similar to other FLC compounds ${ }^{4}$ form V-shaped and hysteresis free transmission voltage curves in a wide temperature range, but only at low frequencies of applied electric field (figure 5).
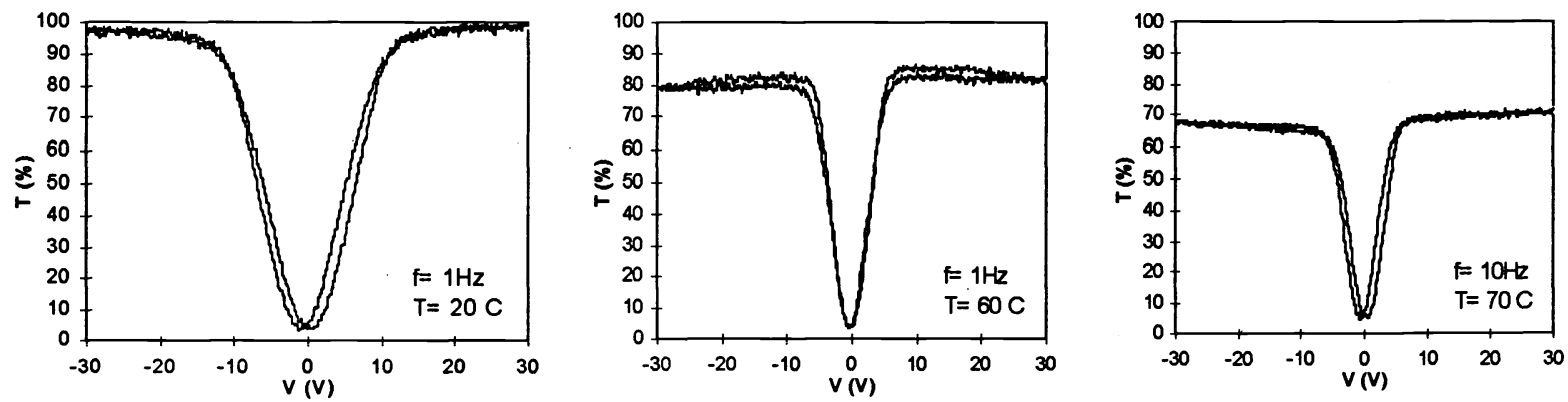

Figure 5 Electro-optic responce of FLC mixture of 4-(2-octyloxycarbonyl)-4-biphenyl ester of 4-decyl-3-chlorobiphenyl-4-carboxylic acid, 4-(2-octyloxycarbonyl)phenyl ester of 4-decyl-3-chlorobiphenyl-4-carboxylic acid, 4-(2-methylbutyloxycarbonyl)phenyl ester of 4-hexyl-3-chlorobiphenyl-4-carboxylic acid (ratio $-2: 2: 1$ ).

\section{EXPERIMENTAL}

The structures of the prepared compounds were confirmed by ${ }^{1} \mathrm{H}-\mathrm{NMR}$ and mass spectroscopy. Phase transition temperatures were measured using a Linkam heating stage having a polarizing PZO microscope and also using a Setaram DSC 92.

4-(6-Decylcyclohex-2-enonoyl-3)benzonytrile (1)

A mixture of $(0.30 \mathrm{~mol})$ of corresponding Mannich salt, $0.31 \mathrm{~mol}$ of ethyl 2-decylacetoacetate and $0.91 \mathrm{~mol}$ potassium hydroxide in $350 \mathrm{ml}$ of dioxane was refluxed during $5 \mathrm{~h}$ under stirring (evolution of dimethylamine!). After cooling to room temperature $600 \mathrm{ml}$ of $10 \%$ sulphuric acid solution was added carefully (evolution of carbon dioxide!) and the product was extracted with benzene. The organic layer was washed with water, dried over anhydrous magnesium sulphate and filtered through a layer of aluminium oxide. The residue obtained after the solvent had been recrystallized from isopropanol. The yield 72 per cent.

4-(6-Decylcyclohex-2-enonoyl-3)benzoic acid (2)

The mixture of $0.02 \mathrm{~mol}$ of 4-(6-decylcyclohex-2-enonoyl-3)benzonytrile (3), $0.08 \mathrm{~mol} \mathrm{KOH}$ in $100 \mathrm{ml}$ ethylene glycol was refluxed with energetic stirring during $10 \mathrm{~h}$. After cooling, the reaction mixture was acidified with $10 \%$ hydrocloric acid, the product was filtered and used, after drying on the air, in the next stage. The yield was $78 \%$.

3.3. The esters $(5 a-d)$ and $(6 a, b)$ were synthesised accordingly ${ }^{1}$.

\section{CONCLUSION}

Prepared results have shown that the ferroelectric LC with low spontaneous polarization can form hysteresis free transmission voltage curves and V-shaped or thresholdless switching

\section{REFERENCES}

1. G.Sasnovski, V.Bezborodov, V.Lapanik, R.Dabrowski, and K.H.Uh, "Synthesis of lateral chlorosubstituted biphenylcarboxylic acids and phenols for optically active esters", Ferroelectrics, 212, 373, 1998.

2. V.Bezborodov, V.Lapanik, G.Sasnovski, "New synthesis and smectic C phase formation in liquid crystalline biphenyls, terphenyls and quaterphenyls", Ferroelectrics, 243, 49, 2000.

3. .S.Bezborodov, R.Dabrowski, J.Dziaduszek, G.Sasnovski and V.F.Petrov, "Synthesis and mesomorphic properties of some cyclohex-2-enone derivatives", Liquid Crystals, 24,.647, 1998.

4. S.T. Lagerwall, "Ferroelectric and Antiferroelectric Liquid Crystals", Willey-VCH, Weinhen and New York, 1999. 